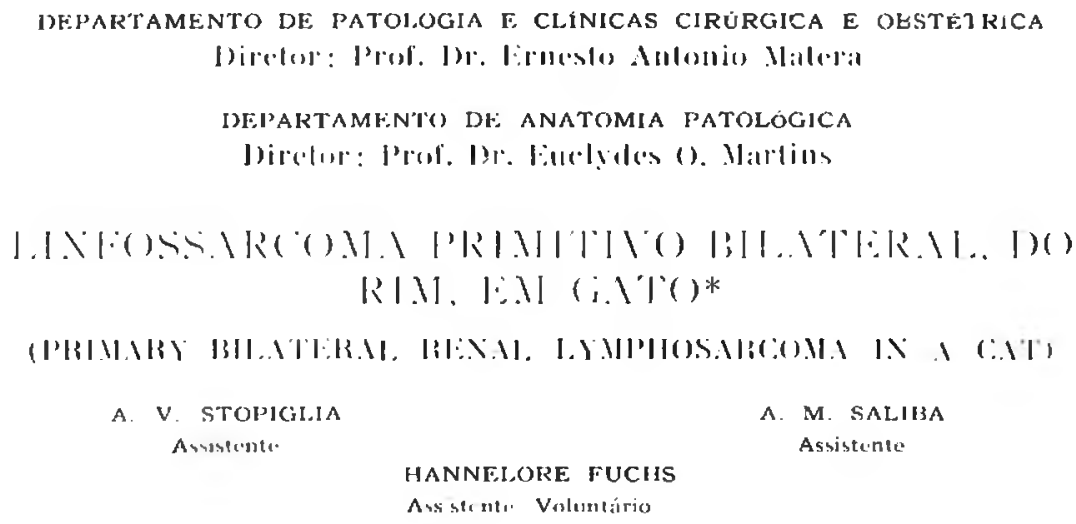

Os tumores renais nos animais domésticos possuem incidência variável, conforme a espécie, sendo os suínos e eqüínos os mais accmetido; (FLIR, 1954).

Quanto aos carnivoros é, indubitàvelmente, rara a prescnça de neoplasias no rim. COTCHIN (1951), ao estudar os neoplasmas nos pequenos animais, de acôrdo com a origem sistêinica, cb crvou que a freqüência de blastomas no aparelho urinário era, nos cães, de apenas 1'; e, nos gatos, de 2 2. FLIR por sua vez, em minucioso trabalho sôbre oncologia rcnal comparada, referindo-se à casuística dêstes tumol'es, nas várias espécies, verifica que apenas $2,5 \%$ occrrem nos felinos, sendo de $1,7 \%$ a incidência em cảes. Mais recentemente, NIELSEN e ARCHIBALD (1955) encontram, após ampla pesquisa bibliográfica, citação de 15 casos de tumores malignos renais em cães e, contribuem, na oportunidade, com mais três observações pessoais.

No capítulo relativo aos tumores na espécie felina, as ncclormações originárias dos tecidos linfóides merecem registro especial, constituindo, mesmo, nestes animais, na opi-

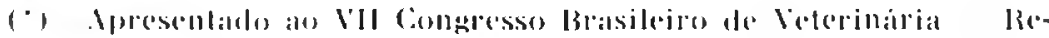
(.j) - 12-1!) (3)(11), 195\%. 
niāo de NIELSEN e HOLZWORTH (1953), um grupo de relativa importancia. Assim, êstes autores, em estudo preliminar sobre o linfcssarcoma visceral dos gatos referem-se aos casos descritcs por PETIT:* (1908), MURRAY* (1908), BALL e COLIET (1931), KIRK (1931), VERARDINI: (193う), VOI,KMANN: (1935), ROBIN* (1935), DAWSON, JUNES e HARVEY * (1937), IPPOLITI* (1939), LOCKE (1948), COTCHIN (1951) e DOUGLAS (1951). Ao ensejo, relatam 14 observe,öcs de linfcssarcomatose, nas quais o descnvolvimento tumoral sc limitou, quase que de modo exclusivo, aos órgàcs abdominais (intestinos, rins e fígado) comprometidos, na maic:ia dos casos, simultancamente. Particularidade digna de nota é, contudc, a refelência apenas de um caso de linfossarccma com localização estritamentc renal, em gato de 15 anos. Posteriormente, HOI_ZWORTH e NIELSEN (1955) retcrnam ao tema e descrevem mais 15 casos, scndo a maior parte sediada nas regiões ccrvical e torácica e, alguns com desenvolvimento em órgãos excepcionalmente afetados (baço, estômago, pâncreas, amígdalas, glândulas salivares, coraçāo) .

A literatura legistra, aında, as observaçōes de PATTERSON e MEIER (1955), referentes a dois casos de linfossarcoma intestinal, e, de COTCHIN (1956) que ac publicar novo estudo sôbre as neoplasias no gato doméstico chama a atencāc para a importância da incidência do linfossarcoma nesta espécie.

O arquivo do Departamento de Anatomia Patológica da Faculdade de Medicina Veterinária acusa ausência absoluta de tumores de qualquer natureza, com sede renal, em gatcs, num total de 133 exames anatomopatológices realizados.

O presente trabalho concernente a tumor primitivo bilatcral do rim, em gato, cferece, portanto, intercisse sob os aspectcs de casuística e de oncclegia comparada, justificando-se a divulgaçāo do caso.

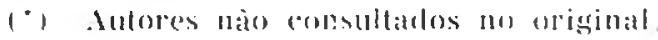




\section{OBSERVAC̣ÃO PESSOAL}

Animal de espécie Fclina, fêmea, s.r.d., de pelagem cinZa, com 12 meses de idade, enviado $\mathrm{cm}$ 12-i-56, para exame. ao Ambulatório de Clínicas Cirúrgica c Obstétrica da Faculdade.

O proprietálio informa que notou aumento de volume no abdcme, com inicio, aprcximadamente, há 2 meses e de crescimento :ápido. Emaciação progressiva. Êste quadro começu a manifestar-se apos o primeiro parto. Apetite e outras grandes funcõcs normais.

Ao exame clínico verificamos: estado de nutrição mau, mucosas aparentes de ccloraçāo rósca; $38.5 .^{\circ} \mathrm{C}$ de temperatura. Batimentos cardíacos na frequêencia de 140 por minuto; bulhas normais. Á inspurāo do abdcme, presença de tumefaçāo bilateral, correspendente às regiōes hịccoridriacas e. em jarte, às iliacas; pela palpação, percebemos que as formações $\mathrm{cm}$ aprêço apresentavam contôrnos e superfície irregulares, consistência firme, estendendo-se respectivamente de cada lado, desde as últimas costelas até fróximo ao limite caudal da regiảo mesogástrica.

Exames de laboratório:

Exame de urina - Vclume: $20 \mathrm{ml}$ remetidos para exame Densidade: 1015

Reação: ácida

Côr: amarela citrina

Aspecto: transparente

Consistência: fluida

Odor: ligeiramente aliáceo

Depósito macroscópico: insignificante

Albumina: vestígios

Urobilina: leve aumento

Sedimente: numcrosas hemácias; numerosos leucócitos isolados; numercsas células epiteliais renais e raras das vias uriná:ia: 


\section{Fxame radiológico}

Relatório 1613/14/1956: "Presença de massa tumoral nas l'egiōes lenais direita e esquerda" (fig. 1).

Evidenciada pelos exames realizados, possibilidade de tumores com localização renal, opinamos pela laparatomia para confirmação do diagnóstico.

\section{Operação}

Scb anestesia geral por inalaçāo, com éter, procedemos a laparotomia mcdiana pré-retro-umbilical.

A inspeção da cavidade permitiu-nos identificar duas forma jos volumosas, à direita e à esquerda, multilobadas, em ccrrespondência à sede respectiva dos rins, sendo a do lado direito relativamente maior do que a oposta. Tais massas apresentaram-se duras ao tacto, móveis, de superficie irregular, sem possuir, todavia, aderências a outros órgãos ou às paredes do abdome.

Executada a expcsição das massas $\mathrm{cm}$ aprêço, aliás, com facilidade, certificamo-nos tratar-se, realmente, de ambos os lins, os quais se exibiam modificados na forma e no aspecto, abrangidos por lesão, possivelmente, de natureza neoplásica (fig. 2) .

Cuidadoso exame da cavidade revelou ausência de quaisquer alteraçōes, er. outras vísceras, cu nas paredes.

Procuramos, em scguida, inicialmente fazer a exérese da massa tumcral correspondente ao rim direito. As tentativas ne se sentido resultaram, porém, infrutíferas, devido ao estado de comprometimento total do órgão, o que nos obrigou a realizar a nefrectomia dêsse lado; a ligadura do pedículo renal foi praticada com fio de algodão duplo.

Nestas circunstâncias, em face da impossibilidade de qualquer intervenção sôbre o rim esquerdo, o mesmo foi recolocado na cavidade.

Finalmente, suturamos os planos profundos, em massa, com pontos separados de fio de algodão e, a pele, com sutura contínua $\mathrm{cm}$ zigue-zague . 


\section{Pós operatório}

A peca excisada foi remetida ao Departamento de Anatomia Patológica, cujo exame histopatológico revelou tratar-se de "Linfossarcoma do rim".

Face ao diagnóstico do tumor, o animal permaneceu em observaçāo.

A evolução pó-cper’atória imediata decorreu normalmente, com cicatrização "p€r primam", após 7 dias.

Novo exame clínico da gata, decorridos 30 dias, acusou pioria no estado geral, perda da vivacidade, apetite diminuícin e evidentes sinais de aumento de volume da neoplasia renal esquerda.

Em 28-8-56 o animal veio a falecer, após curto periodo de anorexia.

\section{Necroscopia}

O cadáver do animal foi enviado ao Departamento de Anatomia Patológica e registrado sob o n. ${ }^{\circ} 4970$.

À necroscopia verilicamos que o animal se encontrava em mau estado de nutrição. O exame de todos os aparelhos nada digno de menção revelou, com excęaāo do sistema urinário, no qual notamos ausência do rim direito, que fôra extirpado cirurgicamente.

O rim esquerdo. de aspecto semelhante ao rim direito, enviado em ocasião anterior ao Departamento de Anatomia Patológica, apresentava-se aumentado de volume e com formações nodulares na superfície.

\section{Exame macroscópico}

Os rins, direito e esquerdo mostravam-se aumentados de volume, medindo aproximadamente $8 \mathrm{~cm} \times 5 \mathrm{~cm} \mathrm{x} 4 \mathrm{~cm}$. Na superfícic dos mesmos notamos formaçōes nodulares cujo tamanho variava desde um grão de milho a uma noz, de coloração cinza esbranquiçada, algumas hemorrágicas. Esstes nódulos tomavam todo o rim dircito e faziam contraste com o tecido renal pràticamente normal, do rim esquerdo. À su- 
perfície de corte verificamos que atingiam a cortical e a medular c eram de aspecto lardáço.

\section{Exame histopatológico}

Fragmentos dos tumcres foram fixados $\mathrm{cm}$ formol a $10 \%$, incluides em parafina, corados pela hematoxilina-eosina, pelo método de Van Gieson, tendo sido fcitas, tambèm, impregnaçõ :s argênticas par'a retículo (Foot-Wilder, Bielschowsky).

O exame microscópico revelcu ser o tumor altamento celular, de estroma conjuntivo pouco desenvolvido e rico em vasos, às vèzes, dilatados e cheics de sangue. As células ass?melhavam-se aos linfoblastos. Eram poliédricas ou arredondadas e de tamanho variável, citoplasma basófilo, e os núcleos eram redondos ou ovais, de cromatina frouxa, com 1 a 2 nucléolos.

Algumas. entretanto, eram piquenas, com citoplasma imperceptivel, mostrando o núcleo com a cromatina condensada, c assemelhavam-se acs linfócitos. Figuras de mitose foram, ainda, notadas.

Certos glomérulos de Malpighi, com caracteristicas normais, persistiam no sicio da massia tumoral. O retículo do tumor cra pouco desenvolvido $\mathrm{c}$ fôra obscrvado nãc só no $\epsilon$ :troma como também ent:e as células tumorais.

I Bagnéstico: linfessarcoma, tipo linfoblástico.

\section{DISCUSSAO}

O caso sugere alguns tópicos que julganos de interésse discutir.

Sob o aspecto clínice, preliminarmente, é cportuno mencionar o mau estado de nutrição apresentado pelo animal ao exame, nào cbstante possuir apetite normal. fázende crer que o tumor estivesse interferindo sôbre o metabolismo, ocorrência, aliás, não averiguada nos casos de linfossarcomatose. Outrossim, a confirmação da presença de nco-fermação em ambos os rins. pela laparotomia, cmbora sugerisce o sacrificio do animal, preferimos, por lôrạ das ci:cunstâncias, rea- 
lizar a nefiectomia unilateral e conservar o animal para observação do caso.

Pouco ou nada se sabe, com exatidão, a respeito da histogênece dos linfossarcomas. Acreditam vários autores (Ricker, Ncthnagel, Freudweiler, Munk e cutros, citados por EWING - 1941). sejam estas neoplasias, no homem. relacionadas à tuberculose. embora nenhuma influência etiológica significativa pcssa ser atribuída a esta moléstia, para os animais, na cpinião de FELDMAN (1932).

Bcrst (cit. EWING) admite que os linfossarcomas nada mais ão do que granulomas infecciosos. Scgundo FELDMAN a gênese do linfessarcoma é devida da proliferação contínua $f$ cxcessiva de células juvens para as quais nāo josca haver um aproveitamento fisiológico; estas células indiferenciadas constituiriam os elementos da neoplasia.

Para c caso em aprêço parece-nos licıto esposar a opinião dêste último autcr, pela ausôncia de quaisqucr outreś fatôr:s que fudessem ocasionar o aparecimento do tumer.

A classificacão dos tumores derivados do tecido linfóide constitui. támbém. motivo de ccntrovérsias. A mais accita, contudc, é a usada por Whartin, Ginsburg, Herbut e al. (cit. WILIIS 1948).

O casc po: nós apresentado de acôrdo com esta classificacão tratä-š de um liniossarccma do tipo linioblástico.

Estas necplasias linfóides, de natureza mais lecalizada, €mbora nāo sejam tào escassas, a julgar pelas publicaçoes na literatusa. verificamos, tedavia, que a sua ocorrência primáila c exclusivamente no rim constitui raridade.

Em crnclusào, o caso estudado no prescrte trabalho retere-se a urr linfossarcoma, tipo linfoblástico, puinário, bilatcral. do lim, em gato, cuja natureza excepcional da ccorrência justifica a aprescontação do mesmo.

\section{SUMIMARY}

Clinical, surgical and pathological data pertaining to a casc of primary lymphesarecoma in a cat, with bilateral kiclncy involvement, are prescnted. 
A bibliographical survey on the incidence of feline lymphatic tumours, as well as a clinical discussion of the case is made.

The authors share Feldman's opinion regarding the origin of lymphosarcomas, classifying the neoplasm by them observed, in accordance with Whartin et al. as a lymphoblastic lymphosarcoma.

Judging from the more specilized literature, this is a rare cbservation to be made in the feline species.

\section{BHBLIOTIRAFIA}

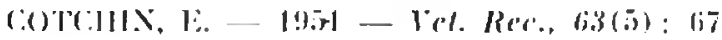

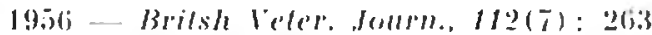

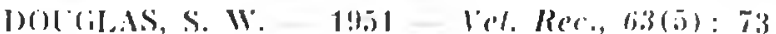

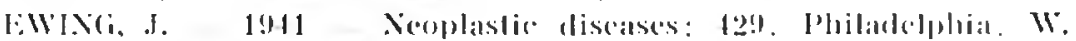
13. Simmolers Commany

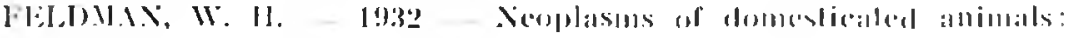

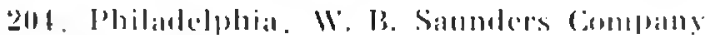

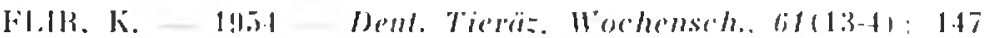

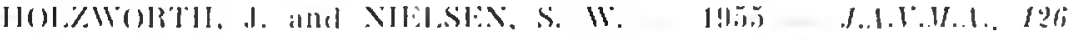
(934): 213

KIlik, 11. 1931- Pet. Rer.. $9(11): 1278$

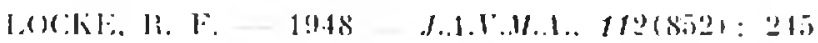

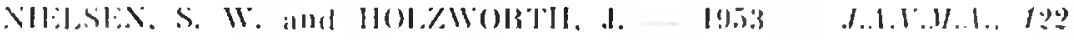
(1) $9121: 18 ! 1$

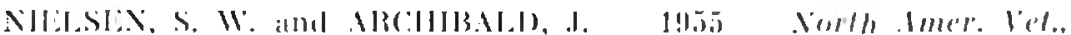
$36: 36$

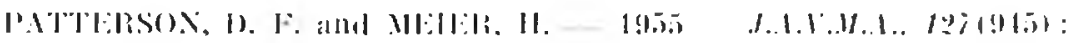
$1 ! 15$

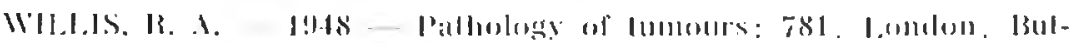

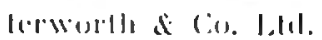




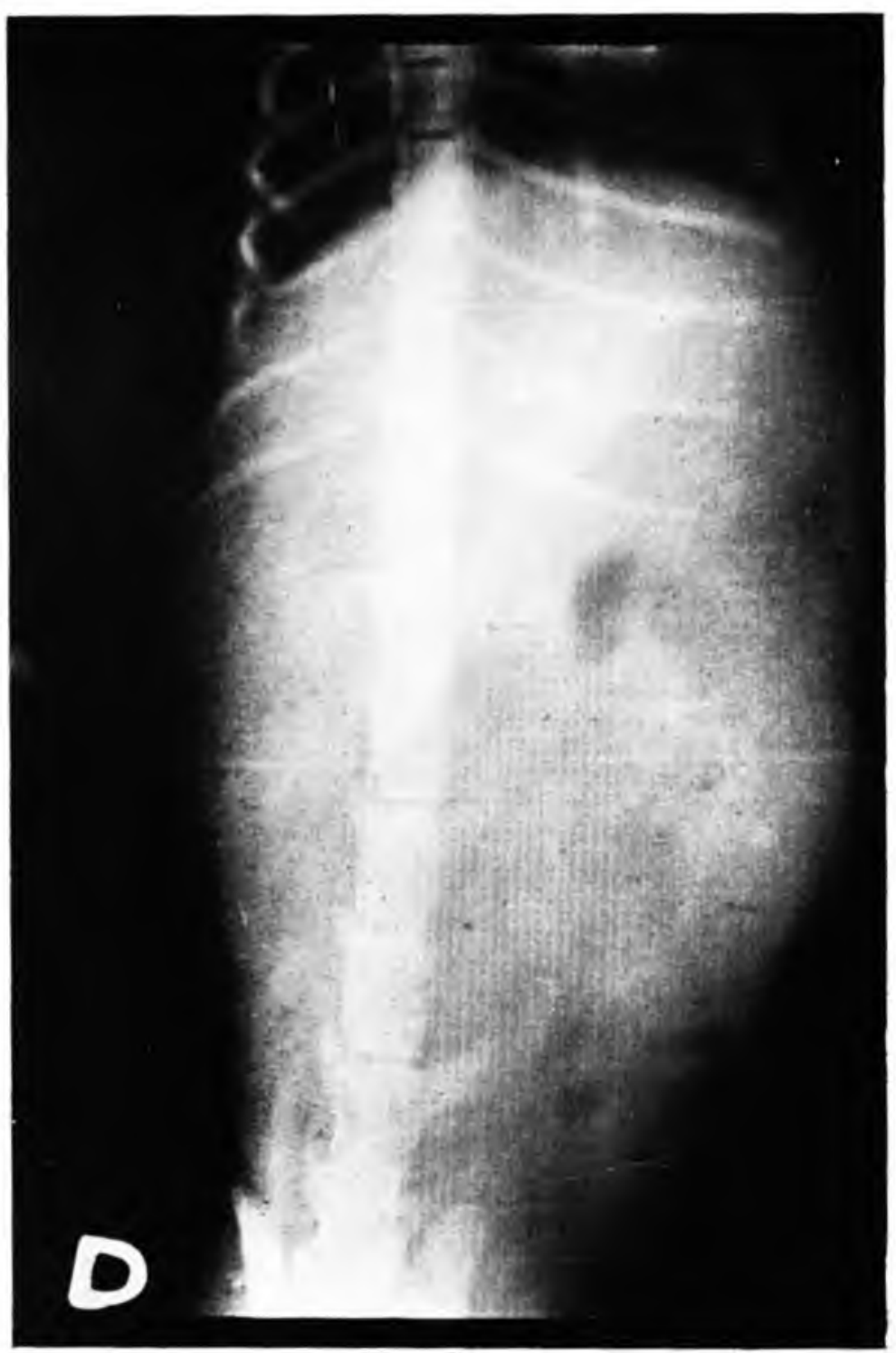

Fig. 1

Asperselo radiográfico do animal. 

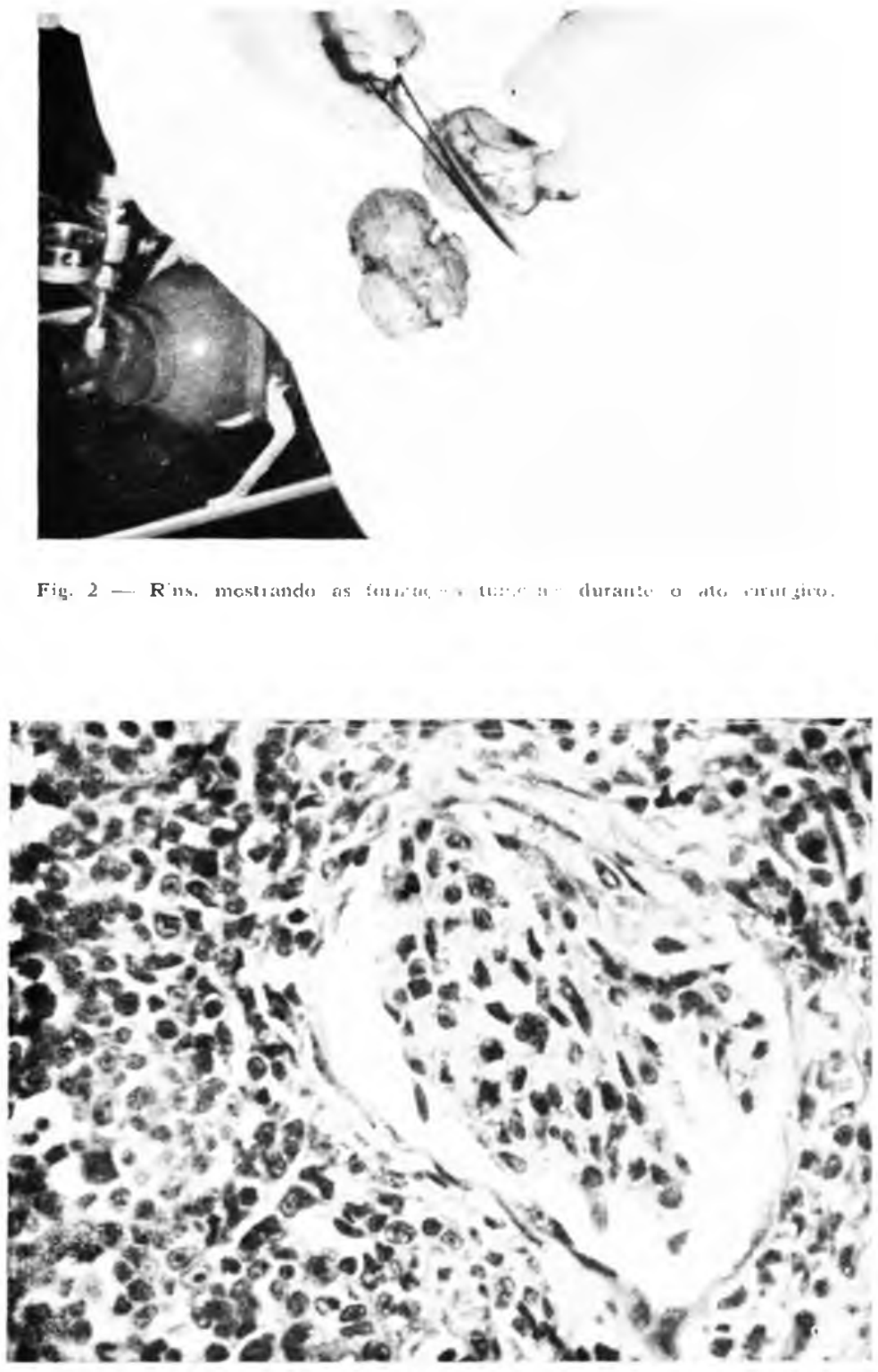

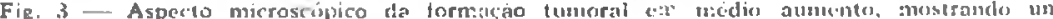
glontérulo de Malpighi. Col. H. E. $480 \mathrm{X}$ 


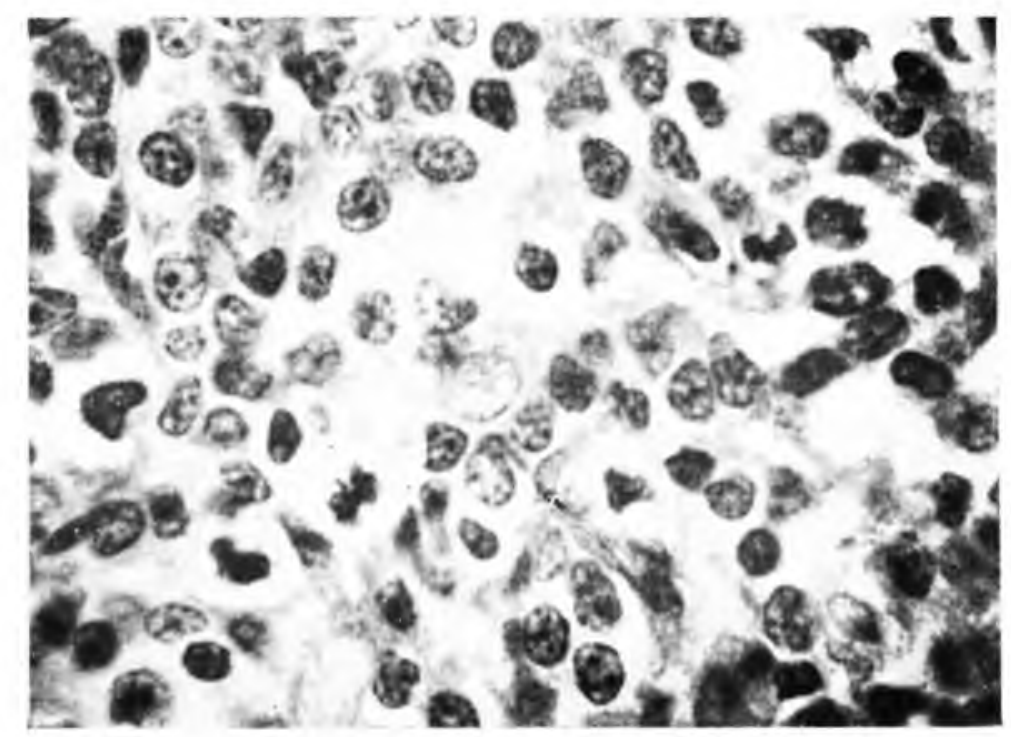

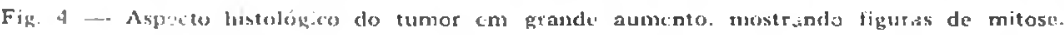
Cul. H E. 1.280 X (inutsio). 